\title{
Developing a Trauma Registry for the Emergency Department of a Tertiary Care Hospital in Egypt: A Step Toward Success
}

\author{
Ahmed A. Khalil ( $\sim$ drahmedaly83@gmail.com ) \\ Ain Shams University Faculty of Medicine https://orcid.org/0000-0002-7218-8167 \\ Maged El-Setouhy \\ Jazan University \\ Jon Mark Hirshon \\ University of Maryland \\ Mohamed El-Shinawi \\ University of Maryland
}

Original research

Keywords: Trauma registry, road traffic injuries, emergency department, Traumatic Injuries

Posted Date: October 15th, 2020

DOI: https://doi.org/10.21203/rs.3.rs-78105/v1

License: @ (i) This work is licensed under a Creative Commons Attribution 4.0 International License.

Read Full License 


\section{Abstract}

Background: Trauma continues to be a common problem affecting global healthcare systems. Accordingly, different types of trauma have been considered major causes of morbidity and mortality with approximately 5 million deaths per year. Road traffic injuries, in particular, have been recognized by the World Health Organization as the sixth leading cause of death in the eastern Mediterranean region. Developed countries have realized the importance of implementing registries across all healthcare systems in order to improve service quality. Unfortunately, Egypt has yet to establish a national trauma registry in its hospitals. Although data banks have been available in a few hospitals, they have been inconsistent.

Purpose: The present study aimed at developing a trauma registry for a major tertiary hospital in Cairo.

Methods: To this end, data from 202 patients admitted to the emergency department of Ain Shams University Hospital due to trauma were collected. Procedures and actions used were then described to create a trauma registry from January to December 2017.

Results: The collected data were statistically analyzed, after which the epidemiological distribution of the trauma patients was described. Accordingly, our results showed that among the included patients, $65 \%$ were men, while most were single, illiterate, and unemployed. Thereafter, statistics regarding trauma circumstances were generated. In

conclusion, the present study found that hospital trauma registries can be established, are essential for improving the quality of healthcare services, and should be utilized ubiquitously throughout the country's hospitals in order to establish a national registry.

\section{Introduction}

Traumatic injuries, one of the main causes of morbidity and mortality, have continued to be major healthcare problems worldwide. Injuries have caused approximately 5 million deaths worldwide every year, with an expected surge in mortality and morbidity by 2030.[1] Injuries have also been among the leading causes of death during the productive years ( $<45$ years of age), leading to significant economic losses. Moreover, injuries account for $8.3 \%$ of age-standardized disability-adjusted life years (DALYs), with road traffic injuries (RTIs) ranked eighth among the 20 leading causes of DALYs in 2012.[2]

Although $90 \%$ of world's road traffic-related fatalities occur in low- and middle-income countries, injury prevention and trauma care programs in these countries have still remained deficient.[3] In 2004, the World Health Organization (WHO) published that RTIs were the sixth leading cause of death in the eastern Mediterranean region (EMR), with 146,000 mortalities and 2.8 million non-fatal injuries.[4]

A trauma registry is a database wherein epidemiological data, processes, and outcomes are documented and stratified. Although trauma registries, which have been considered a cornerstone in quality 
improvement programs, have been widely utilized in advanced countries, considerable deficiencies in the availability of databases have been a concern in developing countries.[5]

Egypt, in particular, has experienced an alarming increase in the burden of traumatic injuries. In 2009, the WHO showed that Egypt had a road traffic death rate of $42 / 100,000$ individuals, one of the highest among EMR countries.[6, 7] Road traffic incidents have been a leading cause of death and hospitalization in Egypt, accounting for $63 \%$ of injury-related deaths and $34 \%$ of non-fatal injuries. Moreover, such incidents particularly affect younger individuals, consequently affecting economic productivity. The high prevalence of road accidents in Egypt and consequent human casualties places considerable socioeconomic and psychological burden on all Egyptian citizens and presents significant challenges for development.[8] However, published data regarding the actual burden of the problem have been scarce, while approximately $53 \%$ of Egyptian hospitals are not included in the national health surveillance system.[7] Moreover, most trauma databases across Egyptian hospitals are variable and inconsistent with regard to coverage and reporting, leading to a substantial gap between available data and actual volume of traumatic injuries.[7]

A number of obstacles hinder the establishment of a sustainable trauma registry within developing countries. However, many of these countries had succeeded in establishing reliable databases using systematic methods.[9]

Ain Shams University hospital, a tertiary care hospital located in Cairo, Egypt, is a massive health institute with numerous available subspecialties. Their surgery hospital alone has 664 beds, which will only continue to expand. Annually, around 48,000 patients visit their emergency room, while approximately 102,000 patients visit their outpatient clinics with 36,000 admissions.[10]

The present study aimed to introduce a basic trauma registry for the emergency department of Ain Shams University Hospital, one of the tertiary care hospitals involved in trauma management within Cairo. Accordingly, we sought to highlight the procedures needed to establish such a registry and efforts required to overcome barriers to its success. Moreover, this study reviewed the results of the registry, including demographic data, circumstances, and causes of various traumatic injuries presented to the emergency department.

\section{Objectives}

To establish a reliable trauma registry for the emergency department of Ain Shams University Hospital and describe our experience with its development.

\section{Methods}

\section{Study design}


This qualitative descriptive study detailed the steps for developing a trauma registry in Ain Shams University Hospital.

\section{Study setting}

This study was conducted at the Emergency Department of Ain Shams University Surgery Hospital. Approval of the Ethical committee of the General surgery department, Ain Shams University and The Ethical committee board in the University of Maryland was obtained before starting the study.

Accordingly, a team composed of two interns, a resident in charge, a medical secretary, and the principal investigator was created. Data from trauma patients admitted into the surgical emergency department on a particular day of the week (i.e., the day our unit was in charge of emergency surgical cases) throughout 2017 were collected by trained house officers using a data collection sheet developed through the collaboration between Ain Shams University and the University of Maryland. Data were collected manually on paper under direct supervision from the surgical resident who ensured that data for all target patients were collected. Data sheets were revised by the principal investigator and forwarded to the medical secretary who entered and coded the data onto a Microsoft access sheet on the department's computer every week. Data on the computer was password-protected, while data collection sheets were locked in a secure desk at our office within the hospital and were only available to the study personnel under the supervision of the principal investigator. After completing data collection, the database was forwarded to a statistician who formulated the results.

\section{Patient inclusion criteria}

- All trauma patients who were admitted to our emergency department once weekly on the day our unit was in charge of the emergency room.

\section{Patient exclusion criteria}

- Trauma patients admitted to the hospital

- Patients with isolated orthopedic trauma given that they were presented to a separate emergency room

- Patients with burns given that they were presented to a specialized burn center

\section{Statistical analysis}

Statistical analysis was performed using SPSS version 23. Qualitative variables were presented as frequencies and percentages, with bar charts being used to graphically demonstrate percentages.

\section{Results}

Throughout 2017, a total of 202 patients suffering from injuries were recorded in our unit [median age: 22 years (interquartile range 15-32), range: 1-62 years]. Table 1 summarizes their sociodemographic characteristics. Patients predominantly lived in urban areas with less than $5 \%$ living in rural areas. 
Additionally, more than half were unemployed, $38.12 \%$ were illiterate, more than half were single, and $46.53 \%$ were smokers. Figure 1 shows the frequencies of patients admitted per month in 2017, while Table 2 shows the characteristics of injuries in the study population. Moreover, around one third of the patients were admitted due to RTIs, while another quarter were admitted due to injuries resulting from interpersonal violence. Tables 3 and 4 provide details related to interpersonal violence and RTIs, respectively. 
Table 1

Sociodemographic characteristics of the study population.

\begin{tabular}{|c|c|c|c|}
\hline \multicolumn{2}{|l|}{ Characteristic } & \multirow{2}{*}{$\begin{array}{l}\text { Number } \\
130\end{array}$} & \multirow{2}{*}{$\begin{array}{l}\text { Percentage } \\
64.36 \%\end{array}$} \\
\hline Gender & Male & & \\
\hline & Female & 72 & $35.64 \%$ \\
\hline \multirow[t]{2}{*}{ Residence } & Urban & 193 & $95.54 \%$ \\
\hline & Rural & 9 & $4.46 \%$ \\
\hline \multirow[t]{5}{*}{ Occupation } & Unemployed & 113 & $55.94 \%$ \\
\hline & Official work & 28 & $13.86 \%$ \\
\hline & Manual work & 33 & $16.34 \%$ \\
\hline & Driver & 8 & $3.96 \%$ \\
\hline & Others & 20 & $9.90 \%$ \\
\hline \multirow[t]{5}{*}{ Education } & Illiterate & 77 & $38.12 \%$ \\
\hline & Literate & 28 & $13.86 \%$ \\
\hline & Essential & 27 & $13.37 \%$ \\
\hline & Secondary/technical & 27 & $13.37 \%$ \\
\hline & University & 43 & $21.29 \%$ \\
\hline \multirow[t]{4}{*}{ Marital status } & Single & 113 & $55.94 \%$ \\
\hline & Married & 76 & $37.62 \%$ \\
\hline & Widow & 7 & $3.47 \%$ \\
\hline & Divorced & 6 & $2.97 \%$ \\
\hline \multirow[t]{5}{*}{ Smoking } & None & 108 & $53.47 \%$ \\
\hline & Cigarette & 25 & $12.38 \%$ \\
\hline & Shisha & 6 & $2.97 \%$ \\
\hline & Both & 63 & $31.19 \%$ \\
\hline & Total & 202 & $100 \%$ \\
\hline
\end{tabular}


Table 2

Injury characteristics.

\begin{tabular}{|c|c|c|c|}
\hline & & Number & Percentage \\
\hline \multirow[t]{3}{*}{ Event exposure } & Interpersonal violence & 66 & $32.67 \%$ \\
\hline & Road traffic & 51 & $25.25 \%$ \\
\hline & Other & 85 & $42.08 \%$ \\
\hline \multirow[t]{6}{*}{ Type of injury } & Polytrauma & 92 & $45.54 \%$ \\
\hline & Cut & 25 & $12.38 \%$ \\
\hline & Concussion & 30 & $14.85 \%$ \\
\hline & Fracture & 14 & $6.93 \%$ \\
\hline & Stab & 28 & $13.86 \%$ \\
\hline & Others & 13 & $6.44 \%$ \\
\hline \multirow[t]{7}{*}{ Site of injury } & Head & 38 & $18.81 \%$ \\
\hline & Chest & 11 & $5.45 \%$ \\
\hline & Abdomen & 18 & $8.91 \%$ \\
\hline & Extremities & 32 & $15.84 \%$ \\
\hline & Multiple sites & 97 & $48.02 \%$ \\
\hline & Not specified & 6 & $2.97 \%$ \\
\hline & Total & 202 & $100 \%$ \\
\hline
\end{tabular}


Table 3

Details related to interpersonal violence.

\begin{tabular}{|c|c|c|c|}
\hline & & Number & Percentage \\
\hline \multirow[t]{7}{*}{ Relation to the assailant } & Parent & 11 & $16.67 \%$ \\
\hline & Child & 4 & $6.06 \%$ \\
\hline & Intimate partner & 3 & $4.55 \%$ \\
\hline & Friend & 15 & $22.73 \%$ \\
\hline & Stranger & 25 & $37.88 \%$ \\
\hline & Others & 7 & $10.61 \%$ \\
\hline & Not specified & 1 & $1.52 \%$ \\
\hline \multirow[t]{6}{*}{ Assailant's education } & Illiterate & 39 & $59.09 \%$ \\
\hline & Literate & 12 & $18.18 \%$ \\
\hline & Essential & 11 & $16.67 \%$ \\
\hline & Secondary/technical & 3 & $4.55 \%$ \\
\hline & University & 0 & $0 \%$ \\
\hline & Not specified & 1 & $1.52 \%$ \\
\hline \multirow[t]{7}{*}{ Assailant's job } & Unemployed & 47 & $71.21 \%$ \\
\hline & Official work & 3 & $4.55 \%$ \\
\hline & Manual work & 11 & $16.67 \%$ \\
\hline & Driver & 2 & $3.03 \%$ \\
\hline & Others & 1 & $1.52 \%$ \\
\hline & Not specified & 2 & $3.03 \%$ \\
\hline & Total & 66 & $100 \%$ \\
\hline
\end{tabular}


Table 4

Details related to road traffic injuries.

\begin{tabular}{|llll|}
\hline \multirow{3}{*}{ Victim status } & & Number & Percentage \\
& Driver & 20 & $39.22 \%$ \\
\cline { 2 - 4 } & Passenger & 12 & $23.53 \%$ \\
\cline { 2 - 4 } & Motor cyclist & 2 & $3.92 \%$ \\
\cline { 2 - 4 } Seat belt* & Pedestrian & 17 & $33.33 \%$ \\
& Yes & 1 & $3.1 \%$ \\
\cline { 2 - 4 } Air bags* & No & 20 & $62.5 \%$ \\
\cline { 2 - 4 } & Not specified & 11 & $34.4 \%$ \\
\cline { 2 - 4 } & Yes & 0 & $0.0 \%$ \\
\cline { 2 - 4 } & No & 21 & $65.6 \%$ \\
\hline Head restraint* & Yes & 0 & $34.4 \%$ \\
\cline { 2 - 4 } & No & 21 & $6.0 \%$ \\
\cline { 2 - 4 } & Not specified & 11 & $34.4 \%$ \\
\hline *Described for vehicle drivers and passengers $(\mathrm{N}=32)$ \\
\hline
\end{tabular}

Prehospital events included transport, first aid at the scene, going home, waiting for family, traffic jam, visiting a clinic, pharmacy, or hospital before arrival at Ain Shams University Hospital, or being directly taken to our emergency room. Recording of prehospital events had been completed for $92.16 \%$ of patients with RTIs. However, prehospital events were largely missing for patients admitted due to other causes (Fig. 2). Table 5 summarizes the prehospital events for patients with RTIs. Data regarding signs of alcohol and drug use, as well as comorbid conditions, were largely missing for injuries other than RTIs. Figure 3 shows the frequencies of comorbid conditions among patients with RTI, while Table 6 presents the details regarding medical examination of injured patients. Finally, Table 7 shows the monthly audit of data entry to confirm its accuracy. 
Table 5

Prehospital events for patients with road traffic injuries.

\begin{tabular}{|c|c|c|c|}
\hline & & Number & Percentage \\
\hline \multirow[t]{5}{*}{ Transport } & Ambulance & 27 & $52.9 \%$ \\
\hline & Taxi & 4 & $7.8 \%$ \\
\hline & Private & 19 & $37.3 \%$ \\
\hline & Other & 0 & $0.0 \%$ \\
\hline & Not specified & 1 & $2.0 \%$ \\
\hline \multirow[t]{2}{*}{ First aid at the scene } & Yes & 12 & $23.5 \%$ \\
\hline & No & 39 & $76.5 \%$ \\
\hline \multirow[t]{2}{*}{ Going home } & Yes & 1 & $2.0 \%$ \\
\hline & No & 50 & $98.0 \%$ \\
\hline \multirow[t]{2}{*}{ Waiting for family } & Yes & 21 & $41.2 \%$ \\
\hline & No & 30 & $58.8 \%$ \\
\hline \multirow[t]{2}{*}{ Traffic jam } & Yes & 28 & $54.9 \%$ \\
\hline & No & 23 & $45.1 \%$ \\
\hline \multirow[t]{3}{*}{ Clinic } & Yes & 0 & $0.0 \%$ \\
\hline & No & 49 & $96.1 \%$ \\
\hline & Not specified & 2 & $3.9 \%$ \\
\hline \multirow[t]{3}{*}{ Pharmacy } & Yes & 1 & $2.0 \%$ \\
\hline & No & 48 & $94.1 \%$ \\
\hline & Not specified & 2 & $3.9 \%$ \\
\hline \multirow[t]{3}{*}{ Hospital } & Yes & 14 & $27.5 \%$ \\
\hline & No & 36 & $70.6 \%$ \\
\hline & Not specified & 1 & $2.0 \%$ \\
\hline \multirow[t]{4}{*}{ Directly transferred to the emergency room } & Yes & 26 & $51.0 \%$ \\
\hline & No & 22 & $43.1 \%$ \\
\hline & Not specified & 3 & $5.9 \%$ \\
\hline & Total & 51 & $100 \%$ \\
\hline
\end{tabular}


Table 6

Details regarding the medical examination of injured patients.

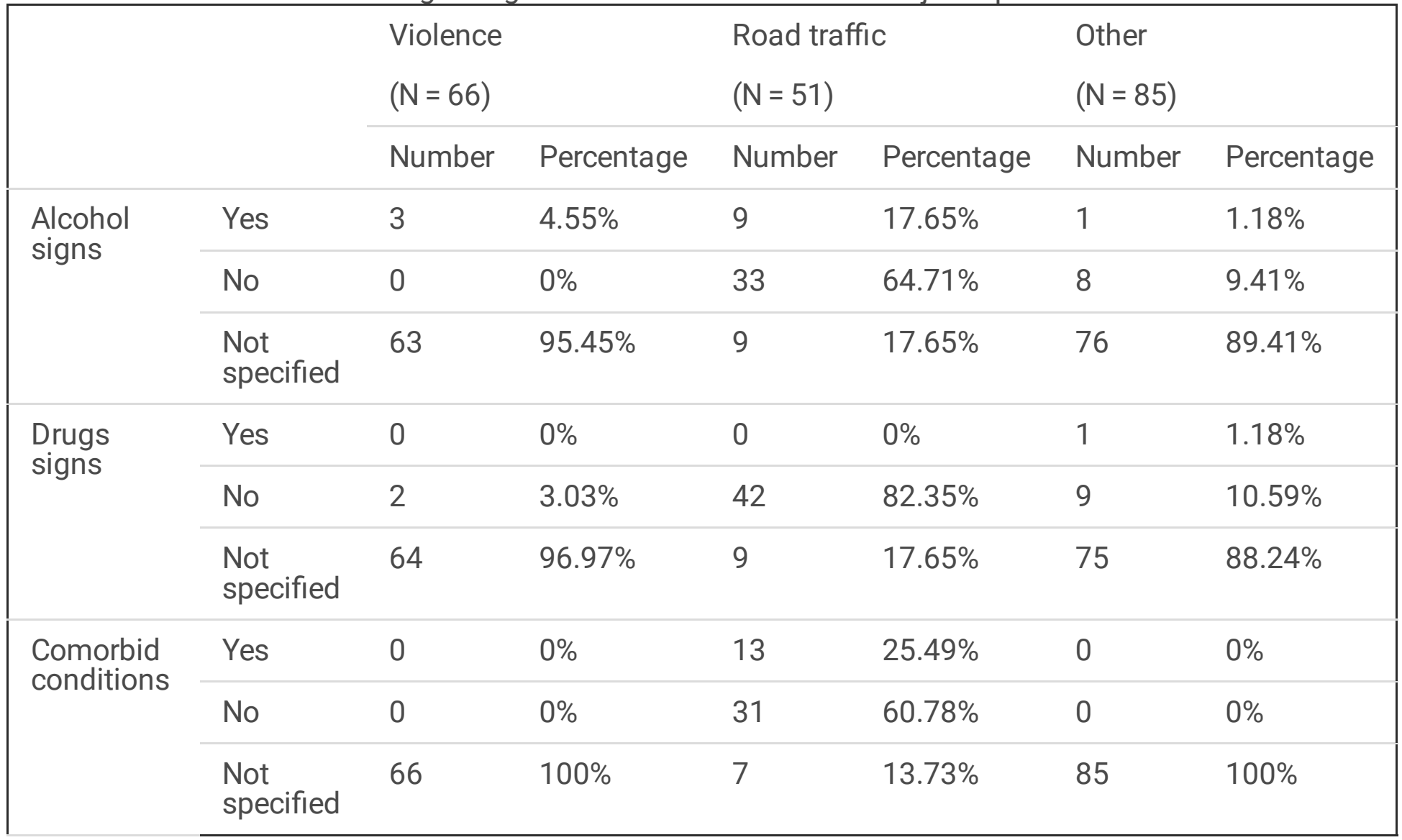


Table 7

Data entry auditing

\begin{tabular}{|llll|}
\hline Month & Number of registered patients & Number of correct data & Accuracy percentage \\
\hline January 2017 & 14 & 10 & $71.4 \%$ \\
\hline February 2017 & 12 & 9 & $75 \%$ \\
\hline March 2017 & 12 & 11 & $91.6 \%$ \\
\hline April 2017 & 20 & 15 & $75 \%$ \\
\hline May 2017 & 4 & 4 & $100 \%$ \\
\hline June 2017 & 25 & 22 & $88 \%$ \\
\hline July 2017 & 30 & 28 & $93.3 \%$ \\
\hline August 2017 & 13 & 13 & $100 \%$ \\
\hline September 2017 & 16 & 15 & $93.75 \%$ \\
\hline October 2017 & 20 & 20 & $100 \%$ \\
\hline November 2017 & 20 & 19 & $95 \%$ \\
\hline December 2017 & 16 & 16 & $100 \%$ \\
\hline Total number of Patients (202) & & \\
\hline
\end{tabular}

\section{Discussion}

Although our trauma team managed to create a trauma registry prototype, further improvements and modifications are needed for our results to be generalized for all trauma patients visiting our hospital. First, the team leader recruited reliable team members who were responsible for doing the work; this team comprised a resident officer, a medical secretary, and two interns. The entire team together with the team leader held discussions and training sessions to explain the concept and determine the necessary steps, subsequently starting data collection in January 2017. During the first 2 months, the interns collected data using the specified sheets under the supervision of the resident officer. The collected data were revised by the team leader and forwarded to the secretary for data entry into the access sheet database. At this time, two obstacles were identified. First, the team was not accustomed to performing data collection tasks, considering that this was not routine. This obstacle was addressed by continuous contact and data collection audits by the resident officer throughout the $24 \mathrm{~h}$ we were responsible in the emergency room. Moreover, the team leader personally revised the data sheets on the following day to confirm that nothing was missing. The second obstacle encountered was that data collection could not be completely entrusted to the two specific interns. This was because we could not ensure that the same two interns could attend to all cases involving injuries for $24 \mathrm{~h}$ throughout the whole study year and because the interns had to rotate departments every 2 months according to their training system. Hence, 
we decided to modify our procedure such that different interns with exchanging roles were responsible for data collection, with their work being continuously audited to confirm the precision of data collection. At the end of the first 6 months, we found that the data collection process became considerably easier, faster, and less time consuming. Moreover, the data collection process had become integrated into the daily work routine, with even the accuracy of data collection remarkably increasing every month. Over the next 6 months, the system was already established, data collection was effortless, and all team members were alert and performed their job efficiently and effortlessly. Data accuracy was considerably high, as shown in Table 7. Ultimately, the trauma registry included 202 trauma patients with all their relevant data.

\section{Lessons learned from establishing the trauma registry}

We conducted a pilot study in which a simple, primitive trauma registry was utilized in our emergency room. By the end of the study, we determined that the concept of a registry of patients containing all relevant data is definitely crucial. Establishing a registry is the very first step for improving the entire healthcare system given that it provides concrete and accurate data that would form the base for any prevention and management protocol. Some of the important findings of the present study was that men were predominantly affected by trauma $(65 \%)$ and that most of the patients were single, unemployed, and illiterate. While RTIs accounted for $25.25 \%$ of all traumas, a surprising $62.5 \%$ of patients involved therein were not using seat belts. Based on this simple information, we can customize injury prevention and management strategies based on our conditions.

\section{Current obstacles}

The following points summarize the most significant obstacles for establishing a sustainable trauma registry in our hospital-a representative tertiary care hospital in Egypt (low-middle income country):

1. Lack of data collection policy provided by the institution.

2. Imprecise data collection due to the work load of the medical suppliers and emergency attendants.

3. Inability to maintain a precise registry without extra effort due to inadequate training of the data collectors.

4. Financial burden on the medical institute related to the expenses of this project.

\section{Steps for continuity and improvement}

1. Teaching the trauma registry process to all residents and interns and performing continuous audits and rehearsals in order to establish an automated process that is not dependent on individuals.

2. Implementing this process as an institutional policy such that it is utilized for all trauma patients in the emergency department and not only in a single unit (as we did in our pilot study).

3. Adding fields in order to collect more data from trauma patients and cover all required information needed for improving healthcare services.

4. Conducting further studies based on the collected data, which would considerably impact the quality of care given to patients. 


\section{Conclusion}

The present study showed that developing a reliable trauma registry in our hospital is feasible. We believe that this is a fundamental step in furthering emergency services and is a cornerstone for quality improvement that must be implemented in our system. Further studies should be designed to upgrade the registry and maximize the benefits obtained from the data collected.

\section{Abbreviations}

(DALYs)..... Disability adjusted life years

(RTIs)..... Road traffic injuries

(WHO).... World Health Organization

$(E M R) \ldots . .$. Eastern Mediterranean Region

\section{Declarations}

Ethical Approval: We obtained the ethical approval before conducting the following research form the institutional review board of Ain Shams University department of Surgery and University of Maryland.

Consent for Publication: Not applicable.

Competing Interests: The authors declare that they have no competing interests.

Funding: The manuscript was funded throughout all its steps from the Fogarty institute in USA.

Authors' Contributions: AK was responsible for data collection, analysis and editing. MS was responsible for the statistics and the study design. JH participated in editing the manuscript and the funding. ME participated in editing and supervising the data collection.

Acknowledgements: We would like to express our gratitude to the residents of our surgical department and the medical secretary for their crucial role in the process of data collection as they exerted all their efforts honestly to help completing their work to the max.

\section{Availability of Data and Materials:}

Please contact author for data requests

\section{References}

1. World Health Organization. Injuries and violence: the facts. Geneva: World Health Organization; (2010). 
2. World Health Organization. Global health estimates 2014 summary tables: DALY by cause, age and sex, 2000-2012. Geneva: World health organization; (2014).

3. Itodo C, Elachi WT, Yongu Odatuwa-OmagbemiD, Odoyoh DD, Mue. Edwin I Ogwuche, and Chukwukadibia $\mathbf{N}$ Ahachi. An epidemiological study of the burden of trauma in Makurdi, Nigeria. Int J Crit Illn Inj Sci. (2015) Apr-Jun; 5(2): 99-102. Doi: 10.4103/2229-5151.158404.

4. Mathers C, Fat D, Boerma J. and the World Health Organization. The Global Burden of Disease 2004 Update. Geneva, Switzerland: World Health Organization; (2004).

5. O'Reilly GM, Joshipura M, Cameron PA, Gruen R. Trauma registries in developing countries: a review of the published experience. Injury. 2013;44(6):713-21.. ().

6. World Health Organization. Road safety in Egypt. Available at: .

7. Puvanachandra P,HoeC,El-Sayed HF,et al. Road traffic injuries and data systems in Egypt: addressing the challenges. Traffic Inj Prev. (2012);13(suppl 1):44-56.

8. World heath organization. Violence, injuries and disability in Egypt. (2020).

9. Zehtabchi S, Nishijima DK, McKay MP, Mann NC. Trauma registries: history, logistics, limitations and contributions to emergency medicine research. Acad Emerg Med. 2011;Jun; 18(6):637-43. Doi:10.1111/j.1553-2712.2011.01083.. ().

10. http://hospitals.asu.edu.eg/ (2015).

\section{Figures}




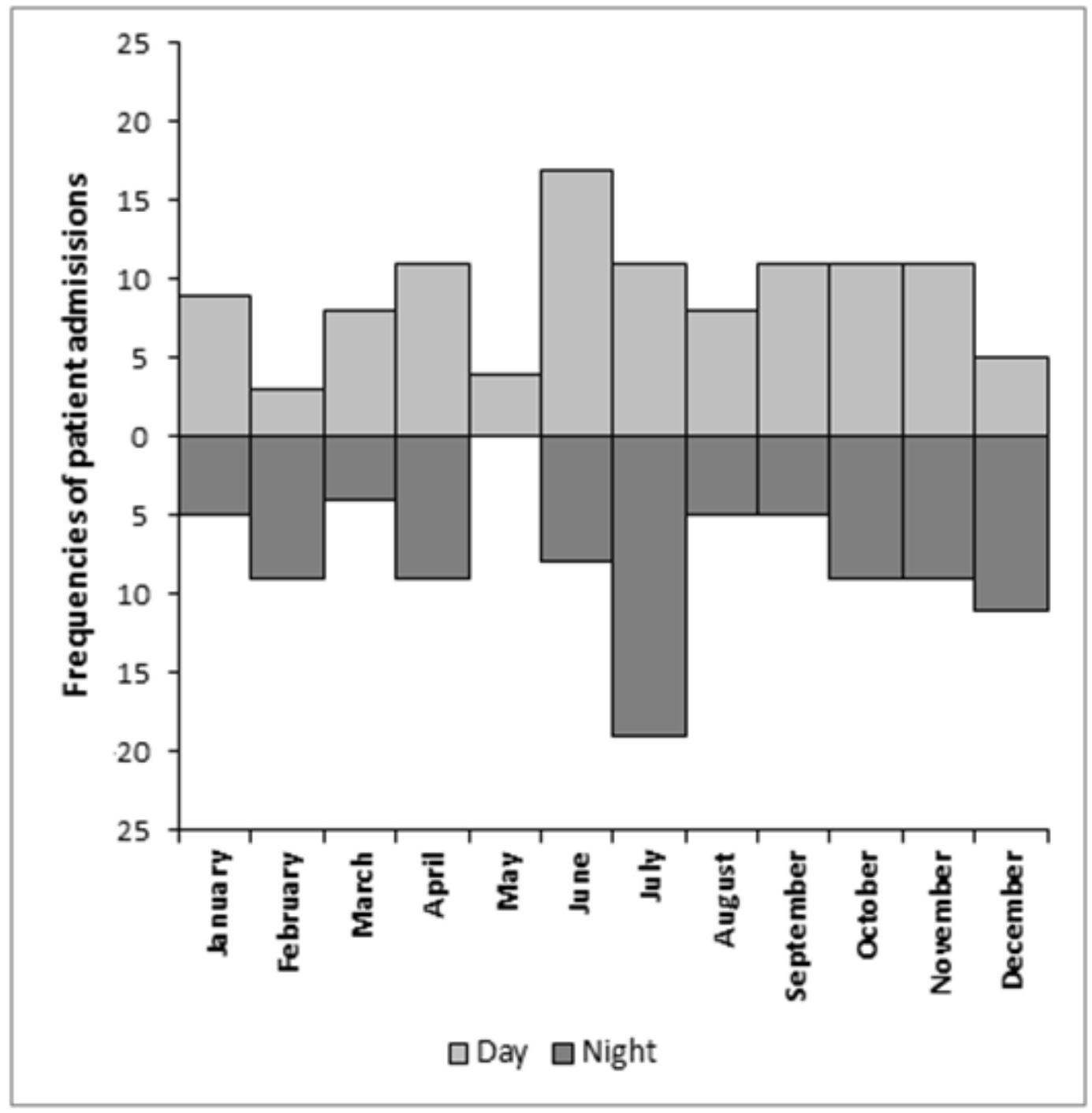

Figure 1

Frequencies of patient admissions per month in 2017. 


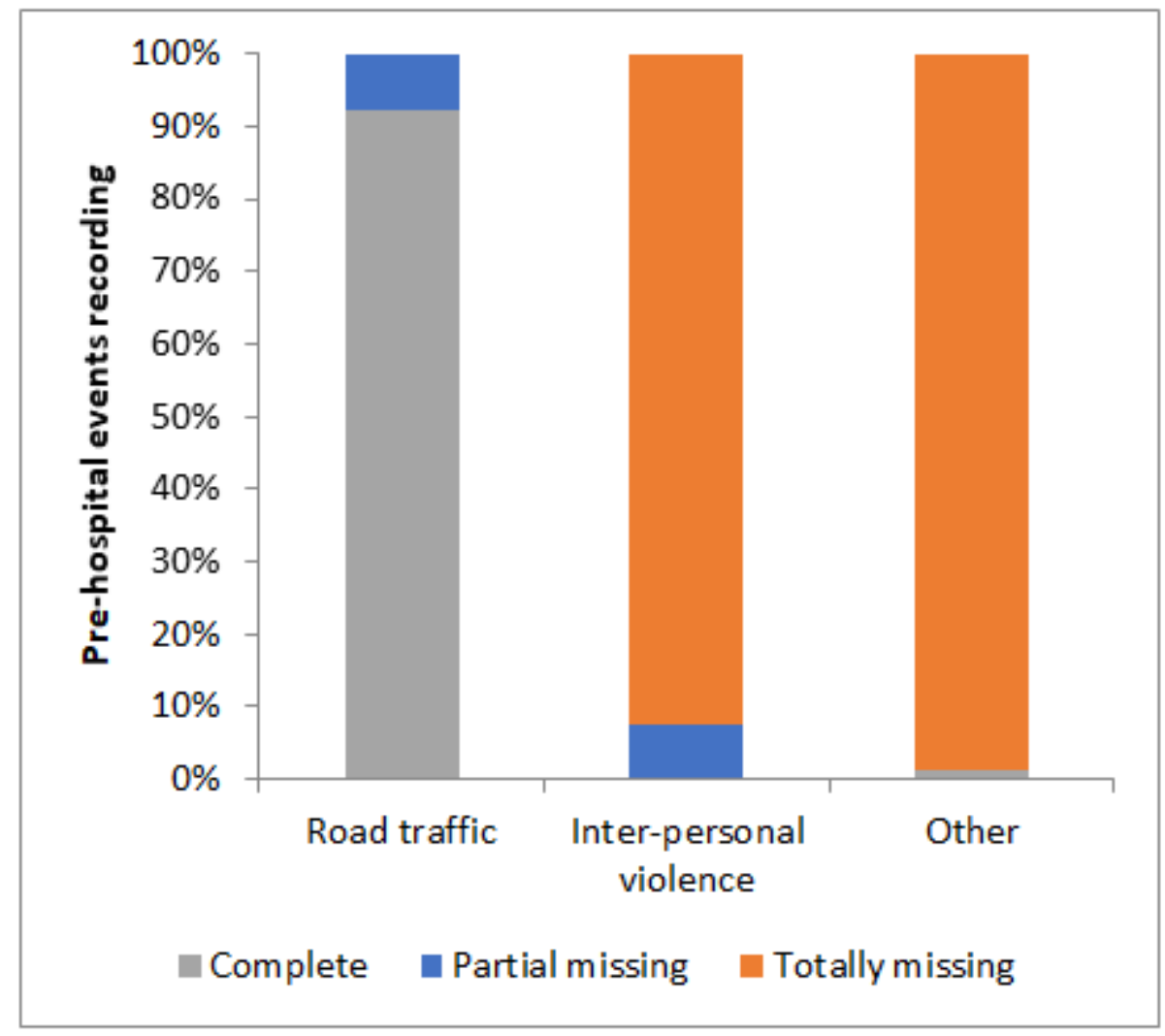

Figure 2

Completeness of prehospital event recording according to cause of injury.

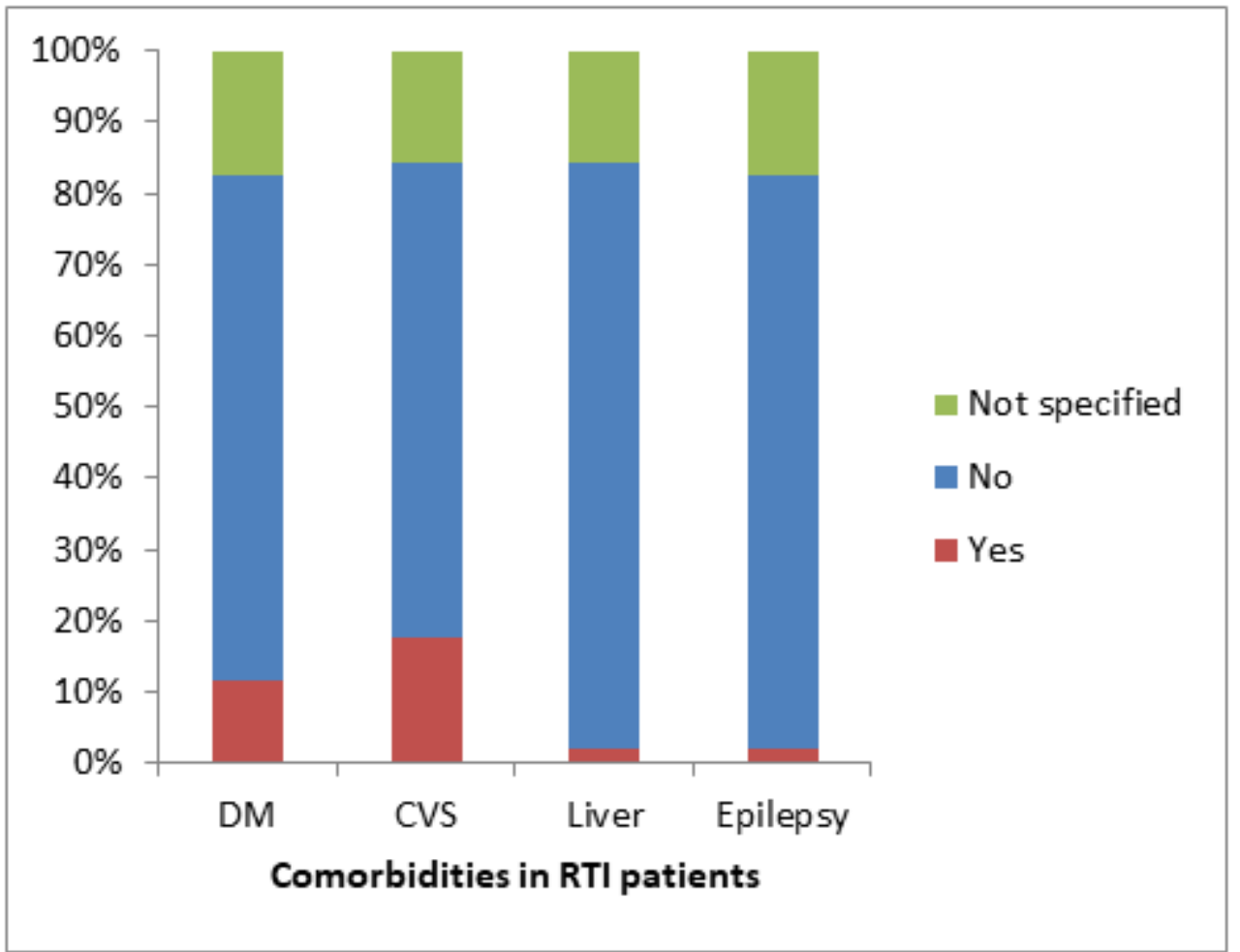

Figure 3 
Frequencies of comorbid conditions among patients with road traffic injuries.

\section{Supplementary Files}

This is a list of supplementary files associated with this preprint. Click to download.

- InjuryDataSheet.pdf 